\title{
Indion 190 resin: Reusable catalyst for the synthesis of quinoxalines and pyrido-pyrazines at ambient temperature
}

\author{
Gangadhar Asaram Meshram *, Shruti Shashank Deshpande, \\ Vipul Amratlal Vala and Pramod Arun Wagh \\ Department of Chemistry, University of Mumbai, Vidyanagri, Kalina, Santacruz (E), Mumbai-400098, India \\ *Corresponding author at: Department of Chemistry, University of Mumbai, Vidyanagri, Kalina, Santacruz (E), Mumbai-400098, India. \\ Tel.: +91.986.9504996; fax: +91.022.26528547. E-mail address: meshramga@chem.mu.ac.in (G.A. Meshram).
}

\section{ARTICLE INFORMATION}

Received: 15 June 2013

Received in revised form: 19 July 2013

Accepted: 22 July 2013

Online: 31 December 2013

\section{KEYWORDS}

\section{1,2-Diamines}

1,2-Dicarbonyls

Indion 190 resin

Solid acid catalyst

Quinoxaline derivatives

Substituted pyrido-pyrazines

\section{Introduction}

Quinoxaline is a privileged ring system and its derivatives represent an important class of nitrogen containing heterocycles as they constitute useful dyes and intermediates in organic synthesis [1]. As depicted in literature, pyrido[2,3b]pyrazines and pyrido[3,4-b]pyrazines are exhibiting promising biological properties and are used for the treatment of malignant tumors and other diseases related to cell proliferations. Functionalized quinoxalines exhibit broad biological activities and have been evaluated as anticancer [2], antiviral [3], antibacterial [4], and kinase inhibition agents $[5,6]$. In addition to their therapeutic properties, quinoxalines have also found applications as dyes [7], organic semiconductors [8] and chemically controllable switches [9]. Consequently, there has been tremendous interest in developing efficient synthetic strategies for preparing quinoxalines due to their widespread applications in the fields of medicinal, industrial and synthetic organic chemistry. Commonly employed method involves condensation of an aryl-1,2-diamine with a 1,2-dicarbonyl in refluxing ethanol or acetic acid for 2$12 \mathrm{~h}$ yielding $34-85 \%$ of product [10]. Several improved methods reported in the literature for the synthesis of quinoxalines include microwave synthesis [11], the use of PEG400 [12], RuCl- $\left(\mathrm{PPh}_{3}\right)_{3}$-TEMPO [13], CAN [14], $\mathrm{CuSO}_{4} \cdot 5 \mathrm{H}_{2} \mathrm{O}$ [15], SA/MeOH [16], montmorillonite $\mathrm{K}-10$ [17], $\mathrm{InCl}_{3}$ [18], $\mathrm{Zn} /$ proline [19], $\mathrm{Ga}(\mathrm{OTf})_{3}[20], \mathrm{HClO}_{4}-\mathrm{SiO}_{2}$ [21], $\beta$-cyclodextrins in water [22], FeMAP [23], $\mathrm{TiO}_{2}$-P25 [24], ZnO-beta zeolite [25], silica-supported antimony(III) chloride [26] as catalysts.

Indion 190 resin, a macroporous strongly acidic cation exchanger with styrene DVB matrix, is used as a heterogeneous catalyst in modern organic synthesis [27,28]. It is a sulphonic acid resin with an exchange capacity of $4.7 \mathrm{meq} / \mathrm{g}$. Particle size of the catalyst ranges from 0.42 to $1.20 \mathrm{~mm}$ and maximum operating temperature is $150{ }^{\circ} \mathrm{C}$. Venturing towards the development of efficient and environmentally benign synthetic strategies, we have investigated the synthesis of substituted quinoxalines and pyrido-pyrazines by condensation of 1,2diamines and 1,2-diketones using Indion-190 resin, an efficient reusable catalyst, at room temperature (Scheme 1).

\section{Experimental}

\subsection{Instrumentation}

The reactions and purity of quinoxalines were monitored by thin layer chromatography (TLC) using glass plates coated with silica gel. The isolated products (5d, 6a-d and 7a-c) were purified by column chromatography whereas (5a-c) were purified by recrystallization. ${ }^{1} \mathrm{H}$ NMR and ${ }^{13} \mathrm{C}$ NMR spectra were recorded on Bruker Avance Spectrospin 300 MHz. All NMR samples were run in $\mathrm{CDCl}_{3}$ and chemical shifts are expressed as $\delta$ relative to internal TMS. IR spectra were obtained on Perkin Elmer FT-IR spectrophotometer spectrum 2000 using potassium bromide pellets. Mass spectra were obtained on Thermo-Finnigm Discovery-Max GC-MS. All the melting points were determined in an open capillary tube using Expo Hi Tech. melting point apparatus.

\subsection{Typical procedure}

To a mixture of 1,2-diamine (1) (1 mmol) and benzil (2) or ninhydrin (3) or acenaphthenequinone (4) $(1 \mathrm{mmol})$ in $\mathrm{AcOH}$ (5 mL), Indion 190 resin $(20 \% / w)$ with respect to 1,2-diamine was added and the mixture was stirred at room temperature. The progress of reaction was monitored using thin layer chromatography. 


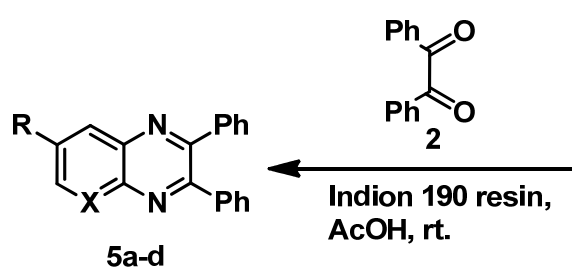<smiles>[R]c1c[Y]([H])c(N)c(N)c1</smiles>

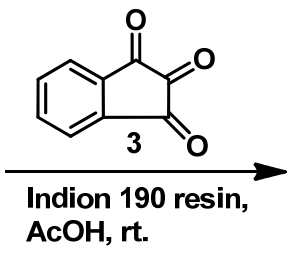

$\mathrm{AcOH}$, rt.<smiles></smiles>

6a-d
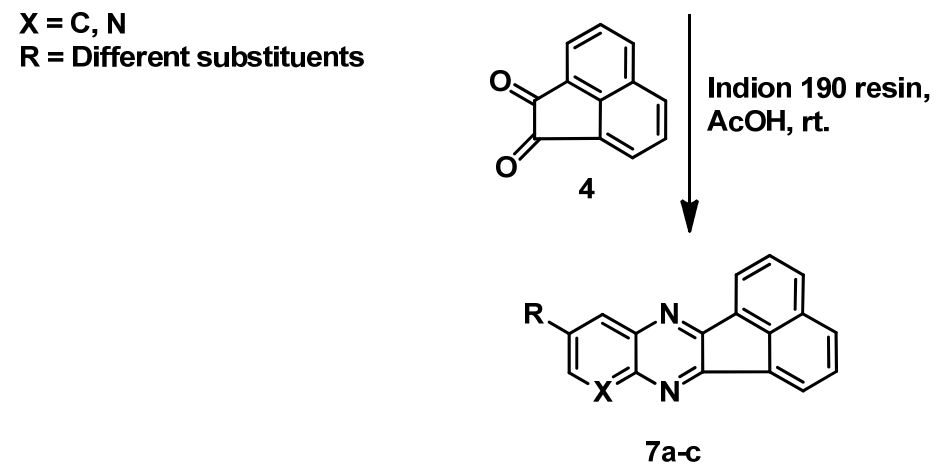

Scheme 1

After completion of reaction, catalyst was filtered and solvent was distilled out. The reaction mass was poured in ice cold water and filtered to afford crude product. The isolated products $(\mathbf{5 a - 5 c})$ were purified by recrystallization with $95 \%$ ethanol whereas (5d, 6a-d and $\mathbf{7 a - c}$ ) were purified by column chromatography.

\section{Results and discussion}

Initially, a model condensation reaction between 1,2phenylenediamine and benzil was subjected to varying reaction conditions. In order to determine the optimum conditions, we first examined the effective catalyst concentration (Table 1) followed by the influence of solvent (Table 2). We also analyzed the reusability of the sulphonic acid resin catalyst (Figure 1). For a typical experiment, 1,2-phenylenediamine and benzil were stirred in $\mathrm{AcOH}(5 \mathrm{~mL})$ at room temperature in presence of Indion 190 resin $(20 \% / w)$. Reaction was completed in 10 min to afford 2,3-diphenyl quinoxaline (Table 3, Entry 5a, $97 \%)$. Encouraged by the outstanding results obtained from the present protocol and to check its further versatility and scope, we have employed various 1,2-diamines and 1,2-dicarbonyls, the results of which are summarized in Table 3.

Table 1. Optimization of the amount of Indion 190 resin a.

\begin{tabular}{lll}
\hline Entry & Catalyst concentration $(\% / w)$ & Yield $(\%))^{\mathbf{b}}$ \\
\hline 1 & 10 & 81 \\
2 & 20 & 97 \\
3 & 30 & 92 \\
4 & 40 & 92 \\
5 & 50 & 92 \\
6 & 60 & 64 \\
\hline \multicolumn{2}{l}{ a Reaction condition: 1,2 -phenylenediamine $(1 \mathrm{mmol})$, benzil $(1 \mathrm{mmol})$, room } \\
temperature and AcOH (5 mL). \\
b Isolated yield.
\end{tabular}

\subsection{Optimization of catalyst}

Catalyst concentration plays a vital role in synthesis of quinoxalines. Application of $20 \% / w$ of Indion 190 resin gave excellent yield of 2,3-diphenyl-quinoxaline (Table 1). At a higher amount of catalyst, the yield of the corresponding product decreases may be due to increase in the acidity of the reaction medium.
Table 2. Effect of solvents a

\begin{tabular}{llll}
\hline Entry & Solvent & Time (min) & Yield (\%) ${ }^{\mathbf{b}}$ \\
\hline 1 & $\mathrm{MeOH}$ & 30 & 94 \\
2 & $\mathrm{EtOH}$ & 75 & 85 \\
3 & $\mathrm{MeCN}$ & 75 & 83 \\
4 & $\mathrm{MeOH}: \mathrm{H}_{2} \mathrm{O}(1: 1)$ & 120 & 90 \\
5 & $\mathrm{EtOH}: \mathrm{H}_{2} \mathrm{O}(1: 1)$ & 120 & 88 \\
6 & $\mathrm{MeCN}: \mathrm{H}_{2} \mathrm{O}(1: 1)$ & 160 & 86 \\
7 & $\mathrm{AcOH}$ c & 10 & 97 \\
\hline
\end{tabular}

a Reaction condition: 1,2-phenylenediamine (1 mmol), benzil (1 $\mathrm{mmol})$, catalyst Indion 190 resin $(20 \% \mathrm{w} / \mathrm{w})$, room temperature and solvent $(5 \mathrm{~mL})$. b Isolated yield.

c Glacial acetic acid AR grade with less than $0.98 \%$ moisture content was used.

Table 3. Synthesis of quinoxalines and pyrido-pyrazines a.

\begin{tabular}{llllll}
\hline Entry & $\mathbf{R}$ & $\mathbf{X}$ & Product & Time (min) & Yield (\%) b \\
\hline 1 & $\mathrm{H}$ & $\mathrm{C}$ & $5 \mathrm{a}$ & 10 & 97 \\
2 & $\mathrm{NO}_{2}$ & $\mathrm{C}$ & $5 \mathrm{~b}$ & 15 & 92 \\
3 & $\mathrm{CH}_{3}$ & $\mathrm{C}$ & $5 \mathrm{c}$ & 10 & 94 \\
4 & $\mathrm{Br}$ & $\mathrm{N}$ & $5 \mathrm{~d}$ & 20 & 90 \\
5 & $\mathrm{H}$ & $\mathrm{C}$ & $6 \mathrm{a}$ & 20 & 92 \\
6 & $\mathrm{NO}_{2}$ & $\mathrm{C}$ & $6 \mathrm{~b}$ & 35 & 83 \\
7 & $\mathrm{CH}_{3}$ & $\mathrm{C}$ & $6 \mathrm{c}$ & 30 & 89 \\
8 & $\mathrm{Br}$ & $\mathrm{N}$ & $6 \mathrm{~d}$ & 25 & 84 \\
9 & $\mathrm{H}$ & $\mathrm{C}$ & $7 \mathrm{a}$ & 25 & 93 \\
10 & $\mathrm{NO}_{2}$ & $\mathrm{C}$ & $7 \mathrm{~b}$ & 25 & 87 \\
11 & $\mathrm{Br}$ & $\mathrm{N}$ & $7 \mathrm{c}$ & 30 & 85 \\
\hline
\end{tabular}

a Reaction condition: 1,2-diammines (1 mmol), 1,2-diketones $(1 \mathrm{mmol})$, catalyst: Indion 190 resin $(20 \% w / w)$, solvent: AcOH $(5 \mathrm{~mL})$, room temperature.

b Isolated yield.

\subsection{Effect of solvent on preparation of quinoxaline}

In order to elucidate the role of the solvents, various solvents were used to evaluate the scope and limitations of the reaction. Solvent optimization study revealed that, glacial acetic acid was the most conducive solvent favoring quinoxaline ring formation (Table 2).

\subsection{Recycling of Indion-190 resin}

The reusability of the catalyst is important for the largescale operation and from an industrial point of view. Therefore, the recovery and reusability of Indion 190 resin was examined. The catalyst was separated and reused after washing with ethanol and drying at $110{ }^{\circ} \mathrm{C}$. Figure 1 illustrates, the catalyst 
can be used four times with consistent yield. The color of the catalyst remains the same even after the four cycles.

In the present synthesis, the activation of the carbonyl oxygen by the acidic proton of Indion 190 resin followed by cyclocondensation with aryl diamine and subsequent loss of water molecule results in the product formation. A variety of quinoxalines and pyrido-pyrazines (Table 3) have been synthesized in good yields ranging from 97 to $83 \%$ irrespective of the complexities and different substituted functionalities. All the synthesized products are known and reported in the literature $[11,29,30]$.

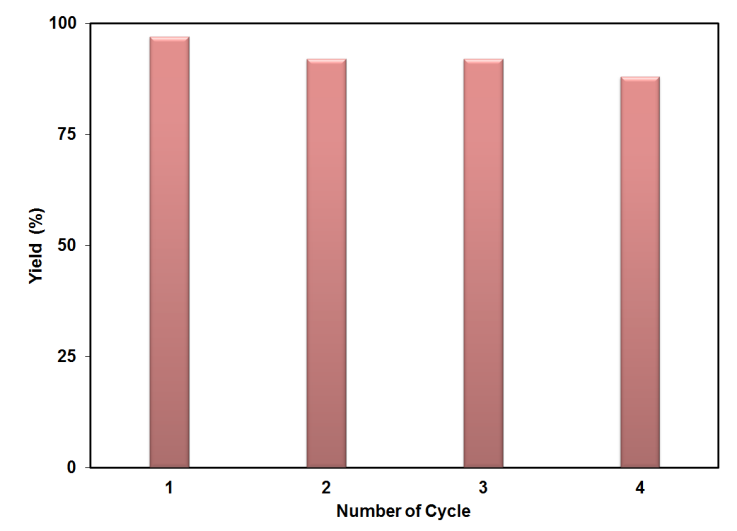

Figure 1. Recyclability of the catalyst.

\section{Conclusion}

In conclusion, commercially available Indion-190 resin, an inexpensive, non-toxic and highly reusable catalyst provides an environmentally benign route for easy access to a variety of quinoxaline and pyrido-pyrazine derivatives. An efficient and highly reusable catalytic system, mild reaction conditions, and short reaction time with high product yield make the present protocol more attractive for practical purposes.

\section{Acknowledgements}

This work was supported by Departmental Research Fellowship provided by Department of Chemistry, University of Mumbai.

\section{References}

[1]. Clauss, E.; Seipelt, I.; Gunther, E.; Polymeropoulos, E.; Czech, M.; Schuster, T. PCT Int. Appl. W02007/054556 2007; Chem. Abstr. 2007, $146,521825$.

[2]. Lindsley, C. W.; Zhao, Z.; Leister, W. H.; Robinson, R. G.; Barnett, S. F.; Defeojones, D.; Jones, R. E.; Hartmann, G. D.; Huff, J. R.; Huber, H.; Duggan, M. E. Bioorg. Med. Chem. Lett. 2005, 15, 761-764.

[3]. Loriga, M.; Piras, S.; Sanna, P.; Paglietti, G. Farmaco 1997, 52(3), 157 166.

[4]. Seitz, L. E.; Suling, W. J.; Renoylds, R. C. J. Med. Chem. 2002, 45, 56045606.

[5]. He, W.; Meyers, M. R.; Hanney, B.; Spada, A.; Blider, G.; Galzeinski, H.; Amin, D.; Needle, S.; Page, K.; Jayyosi, Z.; Perrone, H. Bioorg. Med. Chem. Lett. 2003, 13, 3091-3095.

[6]. Kim, Y. B.; Kim, Y. H.; Park, J. Y.; Kim, S. K. Bioorg. Med. Chem. Lett. 2004, 14, 541-544.

[7]. Katoh, A.; Yoshida, T.; Ohkanda, J. Heterocycles 2000, 52, 911-920.

[8]. Dailey, S.; Feast, W. J.; Peace, R. J.; Sage, I. C.; Till, S.; Wood, E. L. Chem. Mater. 2001, 11, 2238-2243.

[9]. Crossley, M. J.; Johnston, L. A. Chem. Commun. 2002, 1122-1123.

[10]. Brown, D. J., Quinoxalines: SUPPLEMENT II, in The Chemistry of Heterocyclic Compounds, Taylor, E. C., Wipf, P. (Eds.). John Wiley and Sons, New Jersey, 2004.

[11]. Morales-Castellanos, J. J.; Ramirez-Hernandez, K.; Gomez-Flores, N. S.; Rodas-Saurez, O. R. Peralta-Cruz, J. Molecules 2012, 17, 5164-5176.

[12]. Zhang, X. Z.; Wang, J. X.; Sun, Y. J.; Zhan, H. W. Chinese Chem. Lett. 2010, 21, 395-398.

[13]. Robinson, R. S.; Taylor, R. J. K. Synlett. 2005, 6, 1003-1005.
[14]. More, S. V.; Sastry, M. N. V.; Yao, C. F. Green Chem. 2006, 8, 91-95.

[15]. Heravi, M. M.; Taheri, S.; Bakhtiari, K.; Oskooie, H. A. Catal. Commun. 2007, 8, 211-214.

[16]. Darbari, H. R.; Mohandessi, S.; Aghapoor, K.; Mohsenzadeh, F. Catal Commun. 2007, 8, 389-392.

[17]. Huang, T. K.; Wang, R.; Shi, L.; Lu, X. X. Catal. Commun. 2008, 9, 1143 1147.

[18]. Hazarika, P.; Gogoi, P.; Konwar, D. Synth. Commun. 2007, 37, 34473454.

[19]. Heravi, M. M.; Tehrani, M. H.; Bakhtiari, K.; Oskooie, H. A. Catal Commun. 2007, 8, 1341-1344.

[20]. Cai, J. J.; Zou, J. P.; Pan, X. Q.; Zhang, W. Tetrahedron Lett. 2008, 49 7386-7390.

[21]. Das, B.; Katta, V.; Kanaparthy, S.; Anjoy, M. Tetrahedron Lett. 2007, 48, 5371-5374

[22]. Madhav, B.; Murthy, S. N.; Reddy, V. P.; Rao, K. R.; Nageshwar, Y. V. D. Tetrahedron Lett. 2009, 50, 6025-6028.

[23]. Rao, K. T. V.; Sai Prasad, P. S.; Lingaiah, N. J. Mol. Catal. A-Chem. 2009, 312, 65-69.

[24]. Krishnakumar, B.; Swaminathan, M. J. Organomet. Chem. 2010, 695, 2572-2577.

[25]. Katkar, S. S.; Mohite, P. H.; Gadekar, L. S.; Arbad, B. R.; Lande, M. K. Cent. Eur. J. Chem. 2010, 8, 320-325.

[26]. Darbari, H. R.; Aghapoor, K.; Mohsenzadeh, F.; Tala, F.; Asadollahnejad, N.; Badiei, A. Catal. Lett. 2009, 133, 84-89.

[27]. Srinivasula, R. L.; Gangi, R. N. C.; Ram, R. T.; Lingappa, Y.; Bodireddy, M. R. J. Korean Chem. Soc. 2011, 55, 304-307.

[28]. Chaskar, A.; Yewale, S.; Langi, B.; Deokar, H. J. Korean Chem. Soc. 2009, 53, 422-426.

[29]. Kaupp, G.; Reza Naimi-Jamal, M. Eur. J. Org. Chem. 2002, 8, 1368-1373.

[30]. Deady, L. W.; Desneves, J.; Ross A. C. Tetrahedron 1993, 49, 9823 9828 